\title{
Is financial literacy an economic good?
}

\author{
Rubén Castro and Andrés Fortunato
}

ABSTRACT

Financial literacy (FL) is generally regarded as an economic good which individuals choose whether or not to consume depending on how much of a contribution they expect it to make to the quality of their financial decision-making. This construct has not, however, been tested empirically. In this study we analyse variations in FL on the part of individuals who experience major life-cycle events that show up in the data and that can be assumed to have repercussions on their personal finances. The analysis of a panel made up of approximately 12,000 people indicates that there is a correlation between 13 of the 17 selected life events and financial decisions, but only one of those events (job training) is associated with a change in FL. This evidence casts doubt upon the conceptualization of FL as an economic good and is in line with a series of other studies that, for one reason or another, have questioned the soundness of the current conceptual approach to FL. Santiago, Chile. ruben.castro@udp.cl

Andrés Fortunato is a doctoral candidate in the School of Economics of the University of Chile, Santiago, Chile.fortunato@hotmail.cl 


\section{I}

\section{Introduction}

Financial markets are becoming increasingly complex and are becoming accessible to more and more people. Because of this, individuals' ability to optimize their finances is presumed to have a substantive influence on their well-being (see, for example, Hilgert, Hogarth and Beverly, 2003, and Campbell and others, 2011). This is the origin of the concept of "financial literacy" (FL) as a characteristic that has a decisive influence on an individual's ability to optimize his or her financial standing position.

While the different empirical approaches used to measure people's FL have come in for criticism, it can be argued that the levels of FL found in the general population are substantially lower than they should be (Hogarth and Hilgerth, 2002; Miles, 2004; Christelis, Jappelli and Padula, 2005; Lusardi and Mitchell, 2007a and 2007b; Lusardi, Mitchell and Curto, 2010; Landerretche and Martínez, 2011; Van Rooij, Lusardi and Alessie, 2011; Stone and Neumann, 2012, among others). This has consistently been found to be the case in all the countries for which data are available, and FL levels are particularly low among the poorer segments of the population and among women. It has been observed that this FL deficit not only has a detrimental impact on individuals but has also played a harmful role in markets and in recent global financial crises (Gerardi, Goette and Meier, 2010). Many countries have therefore begun to implement programmes designed to boost the population's FL levels in the belief that the social benefits of this type of initiative will far outweigh its costs.

Analyses of such programmes' impact on financial behaviour have not yielded straightforward results, however (see, for example, Lyons and others, 2006; Hathaway and Khatiwada, 2008; Servon and Kaestnert, 2008; Willis, 2009; Mandell and Klein, 2009). A number of authors attribute this to the FL literature's lack of a sound conceptual framework (Mason and Wilson, 2000; Willis, 2008; Remund, 2010, and Huston, 2010).

In order to develop better policies and impact assessments in this area, a fuller understanding of the process of FL accumulation and decumulation (FLAD)

The authors are grateful for valuable assistance received for the project from Marcela Urbina, Olivia Mitchell, Ximena Quintanilla and Eduardo Fajnzylber. is needed. Thus far, only a very few in-depth studies (Delavande, Rohwedder and Willis, 2008, and Agarwal and others, 2009) have focused on how FL levels may change over people's life cycles or over time or how they may be altered by changes in the surrounding environment.

There is no consensus in the literature regarding the conceptualization of FL (Huston, 2010). Mason and Wilson (2000) have looked into the meaning of "financial literacy", while Remund (2010) says that experts and consumer advocates use the term "to describe the knowledge, skills, confidence and motivation necessary to effectively manage money." Clearly, there are a number of different definitions of FL (based on such factors as numeracy, financial behaviour, knowledge and others) but very little clarity about the decision-making process and what role FL plays in that it. ${ }^{1}$

The approach most commonly taken in the literature is to treat FL as an economic good whose accumulation is optimized on the basis of its expected contribution to an individual's decision-making process. This amounts to an implicit adoption of the model of FL as an "information good" (Bates, 1990), although some authors use a human capital model instead (see, for example, Delavande, Rohwedder and Willis, 2008). In both cases, the underlying idea is that FL is an economic good about which individuals arrive at optimization-based consumption decisions. FLAD patterns will therefore presumably be influenced by the expected benefit and expected cost of FL acquisition. If the expected benefit increases or the cost decreases, a person can be expected to acquire more FL. This is the origin of the idea that it is desirable to educate people about the importance of $\mathrm{FL}$ and to reduce the cost and effort involved in acquiring it. Here, this view will be referred to as the "economic model of FL."

\footnotetext{
1 Van Rooij, Lusardi and Alessie (2011), for example, pose questions that allow them to measure numeracy and basic knowledge related to the working of inflation and interest rates, as well as questions designed to measure more advanced financial knowledge related to financial market instruments (stocks, bonds, and mutual funds). Lusardi and Mitchel (2006) and Stone and Neumann (2012) use a measurement of preparedness for retirement. Lusardi (2008) uses a measurement of knowledge about basic financial concepts, while Fajnzylber, Plaza and Reyes (2009) and Hastings and Tejeda-Ashton (2008) focus on variations in the amount of financial information provided to individuals or the format in which it is supplied.
} 
Yet, despite the fact that this approach is so widely used, no empirical assessments have been made of how well the fit between the economic model of FL and FLAD patterns is.

The main objective of this study is to arrive at just such an assessment. In the economic model of FL, the occurrence of an event that has long-term financial implications for a given person will raise the expected value of $\mathrm{FL}$, since the incorporation of new information (the event) may make it necessary to take certain financial decisions. If the occurrence is exogenous to FL, then FL will be expected to increase in response to the event. The impact of events having financially significant implications on individuals' FL was estimated using a representative sample of the Chilean population for the period 2004-2009. The sample corresponds to that used in four rounds (2002, 2004, 2006 and 2009) of a panel survey (the Social Protection Survey); a fifth round was conducted in 2012, but the data from that round are not yet available. These longitudinal data include a module on financial knowledge and skills.

The results of this analysis indicate that there is no significant, consistent variation in FL when an event having substantial financial implications occurs. The study therefore concludes that FL does not behave like an economic good.

The following section covers the data, the selected events, the FL indicators and the statistical analyses used in this study. Sections III and IV report the results and present a discussion of the findings.

\section{II}

\section{Methodology and data}

In the economic model of FL, the benefit of FL is defined as its expected impact on financial decision-making. If the expected trends in people's income and expenditure flows change, and they therefore have a strong reason to re-evaluate their financial situation, then the expected benefit of acquiring FL will rise. If, at the same time, the cost of acquiring FL remains constant, people would be expected to acquire more FL. A comparison of measurements of FL before and after a change in the expected trend of income and expenditure flows ought to reflect a positive effect under these circumstances.

For this study, we used survey data to select a series of observable events that can reasonably be supposed to trigger changes in people's expected income and expenditure flows. These events are of a sort that has far-reaching, multidimensional effects on people's lives and include changes in civil status, health, job training status and household composition. It is unlikely that changes in FL could be the factor that would bring about these transitions, and it is therefore reasonable to assume that they are exogenous to FL. It can also be reasonably assumed that, given the amount of time between one survey and the next (two years), most of the people concerned will have resolved the attendant time constraints and will have avoided paying a higher "price" to acquire FL. Under these assumptions, we should find some extent of a positive correlation between the events in question and people's financial behavior.

The methodology used for this study was based on the regression of an FL indicator with the occurrence of these events while controlling for fixed effects at the individual level and for variables that change over time. Panel data were used for a sample of approximately 14,000 people over a span of seven years. The events were selected beforehand and those that exhibited a correlation with changes in people's financial portfolios were retained. In addition to fixed effects at the individual level, the econometric model incorporated variations in people's incomes as a control variable, and an independent analysis was conducted of each age, sex and educationlevel subgroup.

Another reason for using the events that were selected for this study is that they are ones that usually involve coordination with government agencies, which facilitates the implementation of public policies dealing with personal finances. This is why it is so important to understand the FL patterns associated with these events, which can also create "teachable moments" (i.e., certain types of health and education learning opportunities) (Hansen, 1998; Syvertzen, Stout and Flanagan, 2009; Demark-Wahnefried and others, 2005; McBride, Emmons and Lipkus, 2003; McBride and Ostroff, 2003, among 
others) that may also be applied to the field of FL (Willis, 2008; GAO, 2004; Mandell and Klein, 2007 and 2009). During these teachable moments, people are unusually receptive and are actively seeking out information.

\section{Data}

The data used in this study are drawn from the longitudinal Social Protection Survey, which is conducted roughly every two years in order to obtain information about the operation and development of the social protection system in Chile (Bravo and others, 2004). This study uses data from the last three rounds for which results are available (2004, 2006 and 2009). The questionnaire used in the previous round (2002) was substantially different from the one used in the following rounds, so the 2002 questionnaire could not be used to construct comparable measurements of variables such as income and expenditure. A brief quantitative description of the database is given in table 1 .

The first Social Protection Survey round, conducted in June 2002 and January 2003, used a representative nationwide sample of 17,246 persons registered with the country's pension system. The second round (November 2004-May 2005) included a sample of approximately 3,000 people who were not covered by the pension system. In the third and fourth rounds (2006 and 2009), only people who had been surveyed in one of the previous rounds were covered. The 2006 round included a new module on financial knowledge and noncognitive skills.

Balancing panel data from the last three rounds yields a sample with a total of 12,223 observations per round, with 5,905 men (48.3\%) and 6,318 women $(51.7 \%)$. The distribution of the sample by age group and level of education is shown in table 1.

TABLE 1

Number of observations per Social Protection Survey round, 2004-2009

\begin{tabular}{|c|c|c|c|c|c|c|c|c|c|c|c|c|}
\hline & \multicolumn{4}{|c|}{2004} & \multicolumn{4}{|c|}{2006} & \multicolumn{4}{|c|}{2009} \\
\hline & \multicolumn{2}{|c|}{ Total } & \multicolumn{2}{|c|}{$\begin{array}{c}\text { Current } \\
\text { contributors to the } \\
\text { pension system }\end{array}$} & \multicolumn{2}{|c|}{ Total } & \multicolumn{2}{|c|}{$\begin{array}{c}\text { Current } \\
\text { contributors to the } \\
\text { pension system }\end{array}$} & \multicolumn{2}{|c|}{ Total } & \multicolumn{2}{|c|}{$\begin{array}{c}\text { Current } \\
\text { contributors to the } \\
\text { pension system }\end{array}$} \\
\hline & Number & $\%$ & Number & $\%$ & Number & $\%$ & Number & $\%$ & Number & $\%$ & Number & $\%$ \\
\hline Men & 5905 & 48.3 & 4346 & 54.6 & 5905 & 48.3 & 4200 & 55.1 & 5905 & 48.3 & 4442 & 54.5 \\
\hline Women & 6318 & 51.7 & 3611 & 45.4 & 6318 & 51.7 & 3423 & 44.9 & 6318 & 51.7 & 3699 & 45.4 \\
\hline Age $<35$ & 1663 & 13.6 & 1092 & 13.7 & 1358 & 11.1 & 973 & 12.8 & 976 & 8 & 790 & 9.7 \\
\hline $34<$ age $<55$ & 5040 & 41.2 & 3737 & 47 & 4786 & 39.2 & 3453 & 45.3 & 4321 & 35.4 & 3351 & 41.2 \\
\hline $54<$ age & 5522 & 45.2 & 3130 & 39.3 & 6081 & 49.8 & 3198 & 41.9 & 6928 & 56.7 & 4002 & 49.1 \\
\hline Educ $<=12$ & 9990 & 81.7 & 6122 & 76.9 & 9935 & 81.3 & 5765 & 75.6 & 9951 & 81.4 & 6177 & 75.9 \\
\hline $12<$ educ & 2235 & 18.3 & 1837 & 23.1 & 2290 & 18.7 & 1859 & 24.4 & 2274 & 18.6 & 1966 & 24.1 \\
\hline Total & 12223 & 100 & 7959 & 100 & 12223 & 100 & 7624 & 100 & 12223 & 100 & 8143 & 100 \\
\hline
\end{tabular}

Source: Prepared by the authors, on the basis of data from the Social Protection Survey. 


\section{Selection of events}

The events that were selected meet the following criteria: (i) they are presumably associated with a reassessment of people's long-term financial positions; (ii) they are captured by the available data; and (iii) they exhibit a significant correlation with changes in the consumption of financial goods.

A number of such events were selected beforehand. For each of the consecutive rounds (2004-2006 and 2006-2009), each of these events was coded as 1 or 0 , depending on whether or not it occurred. The initial list included 17 events:

1. Birth of a child

2. Retirement of a member of the household (other than the interviewee)

3. Marriage

4. Divorce

5. Widowed

6. Award of a professional degree

7. Award of a diploma

8. Completion of a job training or in-service training course

9. Learning a trade

10. Commencement of a person's first permanent job

11. Becoming unemployed

12. Re-employment

13. Retirement

14. Disablement

15. Termination of a period of disablement

16. Deterioration in health status

17. Improvement in health status

The frequencies of occurrence of each of these events for each consecutive pair of survey rounds and for each category are shown in table 2 . These 17 events can be grouped into six categories: changes in household structure, changes in civil status, changes in level of education, training, changes in occupational status and changes in health status.

The next step is to confirm that these events actually are associated with a change in financial behaviour. In order to do so, we measured the correlation between the occurrence of these events and changes in four variables that entail some sort of interaction between the person concerned and the financial system. These variables are: (i) changes in savings rate; (ii) changes in total debt over income; (iii) changes in health insurance, and (iv) changes in the amount of insurance.
The econometric model used to find correlations was a linear fixed-effect model, since this allowed us to make sure that any omitted static variable that did not interact with the dynamic variables would not influence the results. The incidence of homogeneous phenomena caused by a round or time effect is partially captured by the constant:

$$
\begin{gathered}
\Delta Y_{i t}=\sum_{j=1}^{17} \beta_{j} \Delta X_{i j t}+\Delta \text { income }_{i t} \\
+\Delta \text { household_income }{ }_{i t}+d_{\text {region it }}+d_{34}+\delta+\Delta \varepsilon_{i t}
\end{gathered}
$$

where $Y$ denotes the variable of interaction with the financial system, $X$ corresponds to the vector of the 17 events and $\delta$ to the constant, $i=1 \ldots N$ indicates the individual concerned, $d_{34}$ is a dummy variable that indicates whether the difference is in the 2006-2009 rounds rather than in the 2004-2006 rounds, $d_{\text {region }}$ is a dummy that captures temporal heterogeneity by region, $\Delta$ income is the variation in the logarithm of the interviewee's inter-round income, _income_household is the variation in the logarithm of the income of the rest of the household members and $t=1,2$ corresponds to the periods 2004-2006 and 2006-2009, respectively. It is assumed that the variables for all the rest of the observables and unobservables are sufficiently fixed to be eliminated from the model or that they change over time in a similar way for all the individuals concerned and are therefore incorporated in the constant. The rest of the assumptions made by Liker, Augustyniak and Duncan (1985) are also used to obtain consistent, unbiased estimators.

The results of these regressions are shown in table 3. Each of the four variables that capture interaction with the financial system is analysed separately.

The criterion used to construct the definitive list of events was the existence of a correlation having a significance level of at least $10 \%$ between the event and one of the indicators of interaction with the financial market. This exercise allows us to immediately rule out four events: retirement of a household member, divorce, and the two types of changes in employment status.

In order to rule out the presence of multicollinearity, inter-event correlations were examined. All of these correlations were under 0.1 except in a few cases during the second period and, even in those cases, the correlation was barely above that figure. 


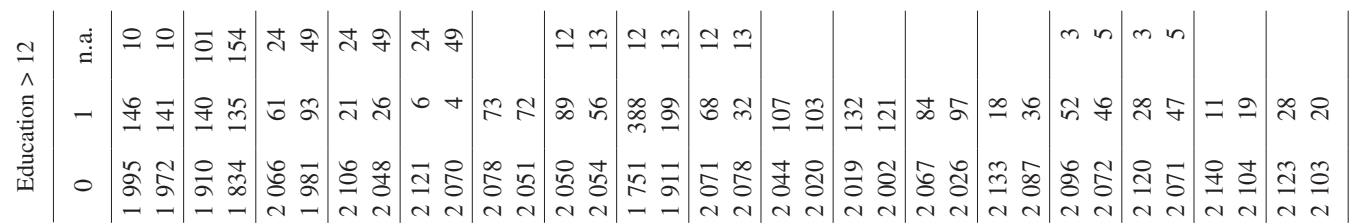

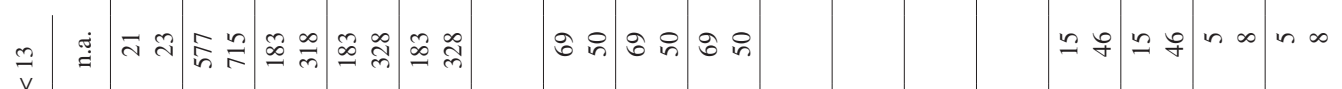

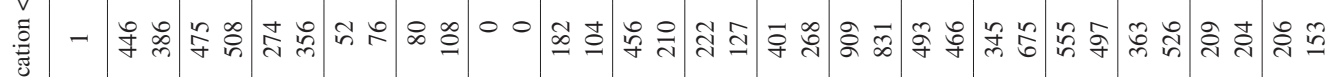

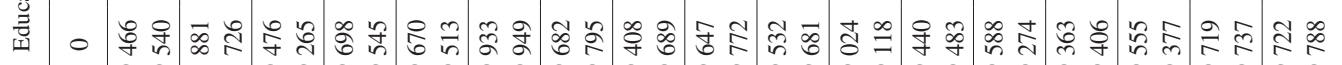

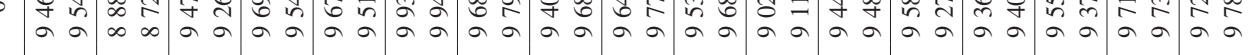
• 曾 o

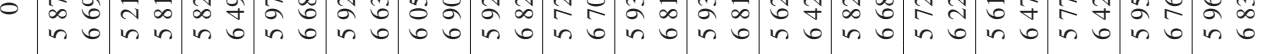

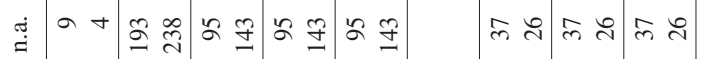

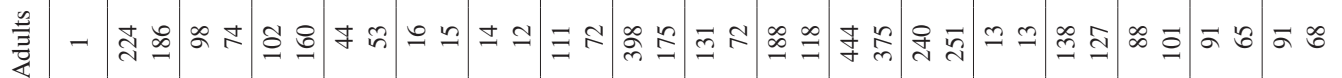

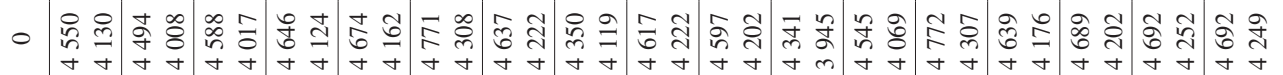

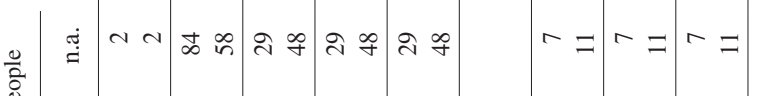

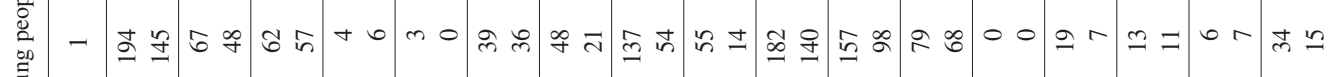

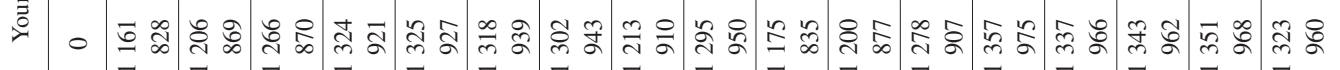

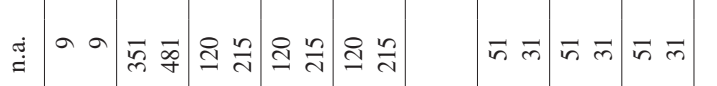

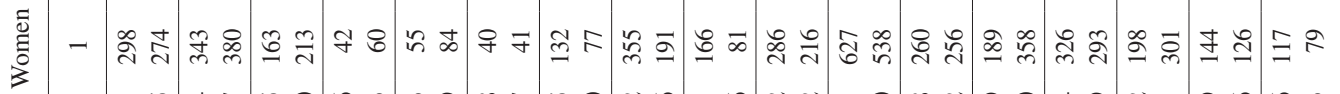

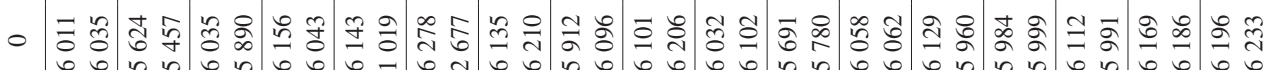
ฮ্่

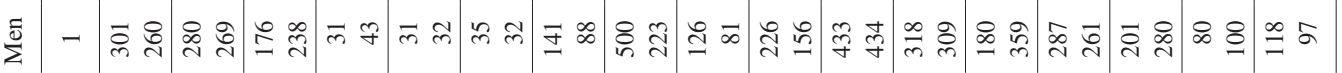

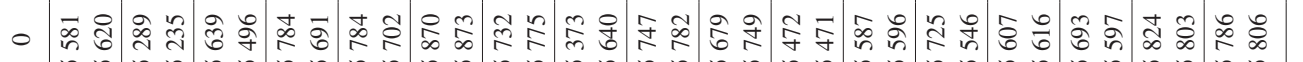

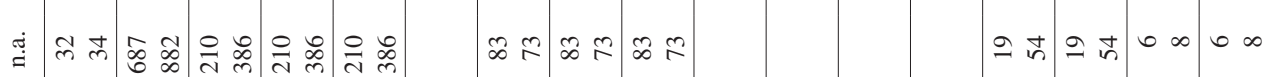

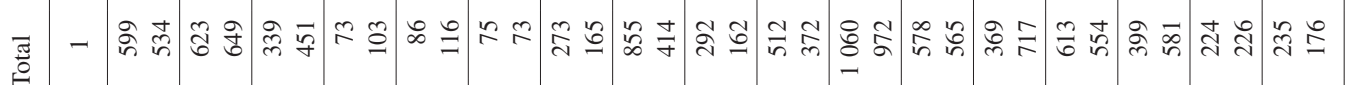

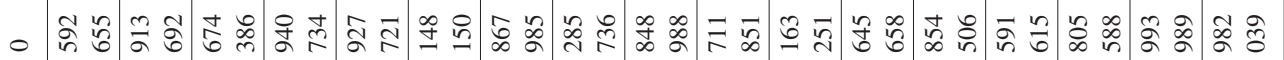

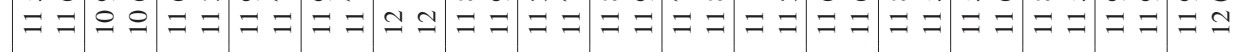

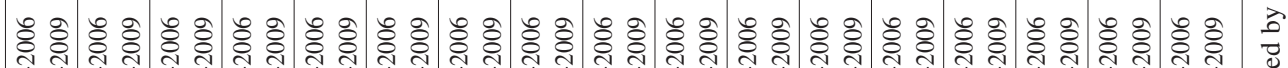

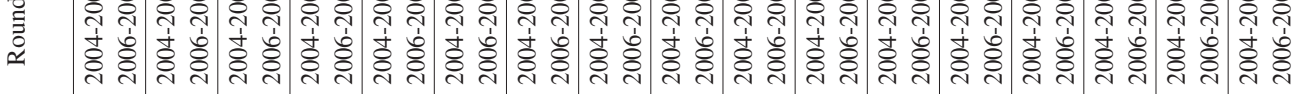

营 
Regressions in first differences, indicators of interaction with financial markets in comparison to the preliminary selection of events, 2006-2009

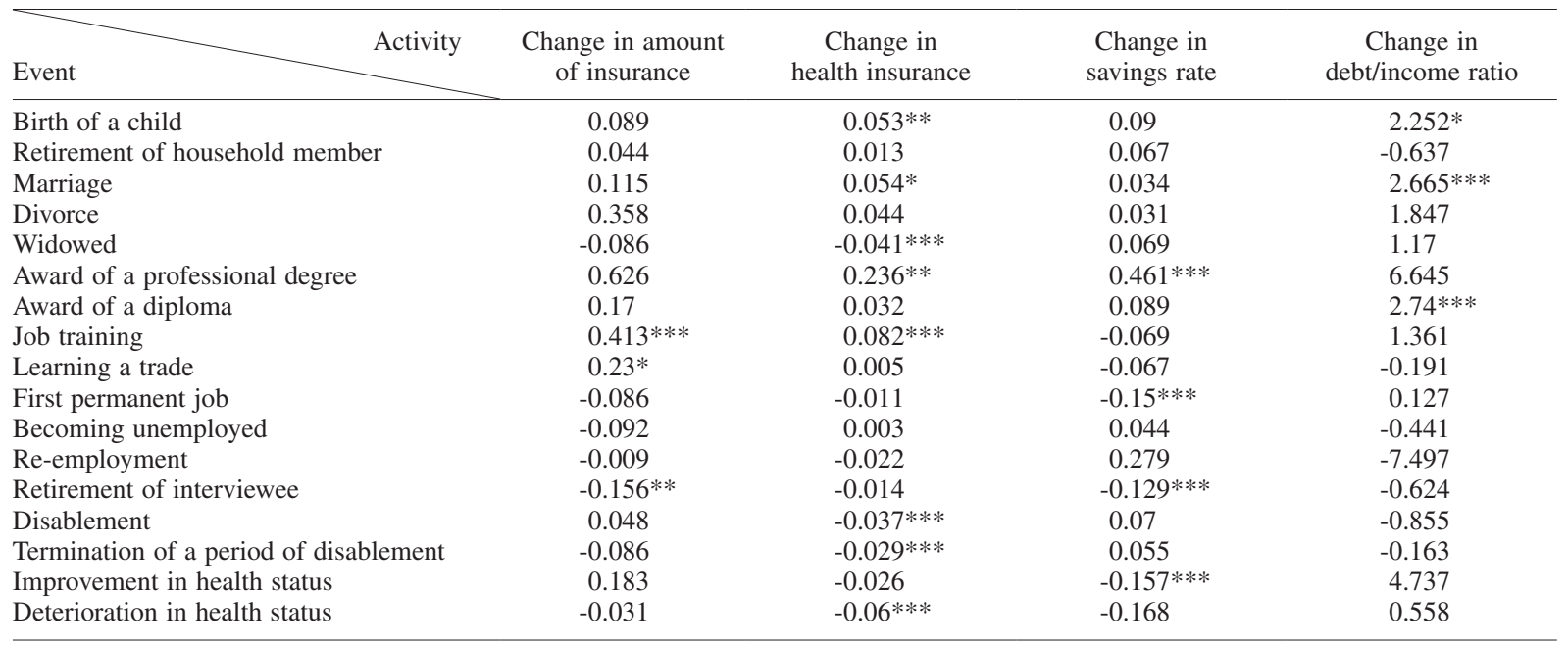

Source: Prepared by the authors, on the basis of data from the Social Protection Survey.

Note: * Significant at $10 \%$; ** significant at $5 \%$; *** significant at $1 \%$.

\section{FL indicators}

Two indicators are used to measure people's stock of FL: their basic financial skills (BFS), which is determined on the basis of information drawn from the last two survey rounds, and their knowledge about the pension system (KPS), which is determined on the basis of information from the last three rounds. This second indicator is intended to capture a different dimension of FL and to replicate the exercise conducted on the basis of BFS while extending it to include the 2004 round.

\section{(a) Measurement of basic financial skills (BFS)}

The indicator used to measure BFS was calculated for the 2006 and 2009 rounds on the basis of responses to six questions. These questions were grouped into a submodule whose purpose was to measure people's ability to understand or perform basic mathematical and financial calculations. The questions were as follows:

1. If the probability of falling ill is $10 \%$, how many people out of every 1,000 persons will fall ill?

2. If five people have winning lottery tickets and the jackpot is two million pesos, how much money will each person receive?

3. Suppose that you have $\$ 100$ in a savings account. The account earns interest at a rate of $2 \%$ per year. If you keep the money in your account for five years, how much money will you have at the end of those five years? (four ranges of figures given).
4. Let's say that you have $\$ 200$ in a savings account. The account interest at a rate of $10 \%$ per year. How much will you have after two years?

5. Suppose that you have $\$ 100$ in a savings account. The account earns interest at a rate of $1 \%$ per year. The rate of inflation is $2 \%$ per year. If you withdraw your money after one year, you will be able to buy something that costs: (i) more than $\$ 100$; (ii) exactly $\$ 100$; (iii) less than $\$ 100$; (iv) don't know or no response.

6. Is the following statement true or false?: "Using a given amount of money to buy shares in one company is less risky than using that same amount of money to buy shares in a number of different companies."

Each response is compared with the correct response to arrive at binary variables (knows/does not know). A quantitative description of the responses given by the total sample to each question is shown in the upper portion of table 4. For all the questions in both rounds, men gave a larger number of correct answers than women did. Young people generally had more correct answers for all the questions except for the question about inflation in 2009, where adults scored higher. More educated people scored higher than their less educated counterparts, with the biggest differences (differentials of over $30 \%$ ) corresponding to the first three questions. As for inter-round differences, the scores on questions 2, 4, 5 and 6 were generally better for the 2006 round, while the scores on questions 1 and 3 were higher for 
Basic financial skills: percentage of correct answers, by round and cohort (Percentages)

\begin{tabular}{|c|c|c|c|c|c|c|c|c|c|}
\hline Question & Round & Total & Men & Women & Age $<35$ & $34<$ age $<55$ & $54<$ age & Educ $<=12$ & $12<$ educ \\
\hline & & \multicolumn{8}{|c|}{ Total sample } \\
\hline \multirow[t]{2}{*}{$\overline{1}$} & 2006 & 44.3 & 49.8 & 39.4 & 60.0 & 46.7 & 39.0 & 37.9 & 73.0 \\
\hline & 2009 & 44.4 & 50.0 & 39.0 & 65.4 & 48.0 & 39.2 & 37.7 & 76.0 \\
\hline \multirow[t]{2}{*}{2} & 2006 & 40.4 & 45.0 & 36.0 & 48.6 & 42.1 & 37.3 & 35.7 & 62.0 \\
\hline & 2009 & 38.4 & 43.1 & 34.0 & 51.9 & 41.8 & 34.5 & 33.2 & 63.6 \\
\hline \multirow[t]{2}{*}{3} & 2006 & 45.7 & 49.5 & 42.2 & 57.9 & 47.7 & 41.6 & 40.6 & 69.0 \\
\hline & 2009 & 47.1 & 51.1 & 43.2 & 63.5 & 50.8 & 42.5 & 41.5 & 72.9 \\
\hline \multirow[t]{2}{*}{4} & 2006 & 1.7 & 2.3 & 1.1 & 2.4 & 1.8 & 1.5 & 0.7 & 6.1 \\
\hline & 2009 & 1.3 & 2.0 & 0.6 & 2.2 & 1.4 & 1.0 & 0.5 & 4.9 \\
\hline \multirow[t]{2}{*}{5} & 2006 & 25.2 & 27.5 & 23.0 & 27.1 & 25.3 & 24.7 & 22.2 & 38.4 \\
\hline & 2009 & 17.8 & 20.0 & 15.8 & 17.8 & 19.5 & 16.8 & 15.3 & 30.3 \\
\hline \multirow[t]{3}{*}{6} & 2006 & 43.6 & 46.0 & 41.3 & 49.7 & 45.5 & 40.7 & 40.2 & 59.5 \\
\hline & 2009 & 40.4 & 43.2 & 37.7 & 48.3 & 45.1 & 36.4 & 37.1 & 55.9 \\
\hline & & \multicolumn{8}{|c|}{ Current contributors to the pension system only } \\
\hline \multirow[t]{2}{*}{1} & 2006 & 51.9 & 54.6 & 48.6 & 62.0 & 51.9 & 48.9 & 45.0 & 73.3 \\
\hline & 2009 & 52.3 & 55.9 & 48.0 & 67.7 & 51.8 & 49.9 & 45.2 & 76.7 \\
\hline \multirow[t]{2}{*}{2} & 2006 & 45.9 & 48.6 & 42.6 & 49.6 & 45.9 & 44.9 & 40.7 & 62.5 \\
\hline & 2009 & 44.5 & 47.0 & 41.5 & 53.4 & 45.2 & 42.3 & 38.9 & 63.8 \\
\hline \multirow[t]{2}{*}{3} & 2006 & 51.6 & 53.9 & 48.9 & 59.0 & 51.5 & 49.6 & 45.9 & 69.4 \\
\hline & 2009 & 54.9 & 56.8 & 52.6 & 66.5 & 55.1 & 52.6 & 49.0 & 74.3 \\
\hline \multirow[t]{2}{*}{4} & 2006 & 2.1 & 2.6 & 1.6 & 1.9 & 2.1 & 2.2 & 0.9 & 5.9 \\
\hline & 2009 & 1.6 & 2.3 & 0.8 & 2.2 & 1.7 & 1.5 & 0.6 & 4.9 \\
\hline \multirow[t]{2}{*}{5} & 2006 & 27.5 & 29.1 & 25.5 & 27.3 & 26.7 & 28.3 & 23.8 & 38.7 \\
\hline & 2009 & 20.2 & 21.8 & 18.3 & 18.4 & 20.9 & 19.9 & 17.2 & 30.2 \\
\hline \multirow[t]{2}{*}{6} & 2006 & 47.3 & 48.6 & 45.6 & 50.7 & 47.2 & 46.3 & 43.3 & 60.0 \\
\hline & 2009 & 44.9 & 46.3 & 43.2 & 48.1 & 47.4 & 42.2 & 41.5 & 55.9 \\
\hline
\end{tabular}

Source: Prepared by the authors, on the basis of data from the Social Protection Survey.

the 2009 round; these differentials were generally less than 5\%, however, except in the case of question 5 (on inflation), where the differential amounts to $7 \%$.

The same information is given in the lower portion of table 4 for the subgroup of persons who were paying into the pension system at the time they were interviewed. In general, the differentials between rounds and categories are much the same as they were in the first case, but the scores are higher In all cases with the exception of the scores for more highly educated persons. This is no doubt due to the existence of a correlation between having a higher level of education and the probability that the person is paying into the pension system.

\section{(b) Measurement of knowledge about the pension system (KPS)}

The 2004, 2006 and 2009 rounds of the Social Protection Survey included over 30 questions designed to measure people's knowledge about the pension system. This makes it possible to construct a KPS indicator that can be used in conjunction with the BFS indicator.

Because the wording of some of the questions differed from one round to the next, and given the findings of Lusardi, Mitchell and Curto (2012) regarding the ways in which differences in the wording of questions can significantly influence the answers given, we decided to use only those questions which were worded in the same way in all three rounds. This left us with 11 questions:

1. Do you know what percentage of your taxable income is deducted (was deducted or would be deducted) each month for social security tax? [Between 11.1\% and 13]

2. Do you know how the pension fund management boards (AFPs) calculate pension benefits? [On the basis of the balance in the individual pension account, retirement age or other factors]

3. Do you know about or have you heard about the Voluntary Retirement Savings (Ahorro Previsional Voluntario (APV)) system that has been in place since 2002?

4. Do you know how much you have in your individual pension account?

5. Do you know how much of a commission your AFP charges for managing your funds?

6. Doyou know about or have you heard about multi-funds?

7. Do you know how many different types of funds there are? [5] 
8. Do you know what type of fund your pension contributions are in?

9. By law, at what age can a man begin to draw his pension? [65]

10. By law, at what age can a woman begin to draw her pension? [60]

11. Do you know what the different types of oldage pensions are? [Scheduled withdrawals, life annuities, fixed-term withdrawals with a deferred life annuity and immediate life annuities with scheduled withdrawals]

The responses to questions 1, 2, 7, 9, 10 and 11 can be checked, whereas the answers to the other questions consist of statements about the person's knowledge. Bravo and others (2004, 2006 and 2008) report some discrepancies between self-reported knowledge and actual knowledge, but they nonetheless find a close correlation between the two. Chan and Huff (2003) find that responses regarding self-reported knowledge provide supplementary data about the importance that people attribute to the information referred to in the question and about their degree of assurance in that regard. Landerretche and Martínez (2011) suggest that, in order to avoid overestimating the parameters in question, the results for these types of responses should be regarded as the upper limit for accurate results when the time comes to interpret them, with the assumption being that the actual value is lower.

It is very important to note that several of these questions are posed only to people who are paying into the pension system at the time that they were interviewed. The estimates discussed in the following section include this subsample so that the results for BFS and KPS can be compared. As in the case of the BFS indicator, the responses are coded in order to obtain binary variables (correct/ incorrect or knows/does not know). The percentages of correct answers in each round in each of the various categories are given in table 5 .

TABLE 5

Knowledge about the pension system: percentage of correct answers, by round and cohort, 2006-2009

(Percentages)

\begin{tabular}{|c|c|c|c|c|c|c|c|c|c|}
\hline Question & Round & Total & Men & Women & Age $<35$ & $34<$ age $<55$ & $54<$ age & Educ $<=12$ & $12<$ educ \\
\hline \multirow[t]{2}{*}{1} & 2004 & 22.5 & 24.0 & 20.8 & 26.8 & 22.3 & 21.3 & 19.4 & 33.0 \\
\hline & 2006 & 19.4 & 20.0 & 18.6 & 24.2 & 19.1 & 18.2 & 16.3 & 29.4 \\
\hline \multirow[t]{3}{*}{2} & 2004 & 10.8 & 12.0 & 9.4 & 10.3 & 10.8 & 11.1 & 8.6 & 18.1 \\
\hline & 2006 & 11.4 & 11.9 & 10.8 & 10.9 & 10.8 & 12.2 & 9.5 & 17.6 \\
\hline & 2009 & 13.1 & 14.4 & 11.5 & 14.7 & 12.3 & 13.4 & 10.8 & 20.4 \\
\hline \multirow{2}{*}{3} & 2006 & 61.8 & 61.6 & 62.1 & 66.0 & 62.8 & 59.4 & 55.2 & 82.8 \\
\hline & 2009 & 44.3 & 44.3 & 43.6 & 44.8 & 45.8 & 42.9 & 37.3 & 67.3 \\
\hline \multirow[t]{3}{*}{4} & 2004 & 50.2 & 53.8 & 46.0 & 44.4 & 51.7 & 50.5 & 47.4 & 59.6 \\
\hline & 2006 & 50.1 & 53.1 & 46.3 & 41.3 & 52.0 & 50.6 & 47.5 & 58.4 \\
\hline & 2009 & 43.7 & 46.2 & 40.6 & 35.3 & 45.4 & 43.9 & 41.4 & 51.3 \\
\hline \multirow[t]{3}{*}{5} & 2004 & 3.1 & 4.0 & 1.9 & 2.3 & 3.2 & 3.2 & 2.2 & 5.8 \\
\hline & 2006 & 4.9 & 5.7 & 3.9 & 4.7 & 4.7 & 5.2 & 3.6 & 9.0 \\
\hline & 2009 & 5.1 & 5.8 & 4.3 & 5.8 & 4.9 & 5.2 & 3.8 & 9.3 \\
\hline \multirow{2}{*}{6} & 2006 & 40.9 & 42.8 & 38.6 & 42.3 & 41.5 & 39.8 & 32.7 & 67.2 \\
\hline & 2009 & 41.5 & 43.5 & 39.2 & 45.1 & 42.3 & 40.2 & 33.1 & 69.6 \\
\hline \multirow[t]{3}{*}{7} & 2004 & 17.9 & 18.8 & 16.9 & 17.6 & 18.4 & 17.5 & 12.6 & 36.0 \\
\hline & 2006 & 17.1 & 18.4 & 15.5 & 18.7 & 17.0 & 16.7 & 12.0 & 33.5 \\
\hline & 2009 & 24.5 & 26.2 & 22.4 & 27.1 & 24.5 & 23.9 & 17.6 & 46.9 \\
\hline \multirow[t]{3}{*}{8} & 2004 & 29.4 & 31.2 & 27.1 & 31.1 & 30.2 & 27.7 & 21.6 & 55.3 \\
\hline & 2006 & 30.2 & 32.6 & 27.2 & 31.4 & 30.5 & 29.4 & 22.7 & 53.8 \\
\hline & 2009 & 35.0 & 37.6 & 31.9 & 39.2 & 36.0 & 33.4 & 26.7 & 62.3 \\
\hline \multirow[t]{3}{*}{9} & 2004 & 82.9 & 83.8 & 81.8 & 76.6 & 83.3 & 84.7 & 81.5 & 87.7 \\
\hline & 2006 & 86.1 & 87.6 & 84.4 & 81.1 & 85.7 & 88.1 & 84.5 & 91.5 \\
\hline & 2009 & 86.8 & 90.6 & 80.4 & 79.3 & 85.9 & 89.0 & 85.6 & 90.7 \\
\hline \multirow[t]{3}{*}{10} & 2004 & 79.0 & 77.7 & 80.6 & 74.1 & 78.6 & 81.1 & 77.0 & 85.8 \\
\hline & 2006 & 81.6 & 81.4 & 82.4 & 77.6 & 81.6 & 82.8 & 78.8 & 90.7 \\
\hline & 2009 & 73.9 & 73.7 & 74.1 & 70.3 & 73.8 & 74.8 & 71.4 & 82.1 \\
\hline \multirow[t]{2}{*}{11} & 2004 & 1.1 & 1.3 & 0.8 & 0.5 & 1.2 & 1.2 & 0.6 & 2.9 \\
\hline & 2006 & 9.1 & 10.4 & 7.5 & 4.8 & 8.0 & 11.6 & 6.7 & 16.8 \\
\hline
\end{tabular}

Source: Prepared by the authors, on the basis of data from the Social Protection Survey. 
Here again, with the exception of the question about the age at which women can retire, men gave a larger percentage of correct answers to all of the questions in all of the rounds than women did. The ranking in terms of age group is not as clear here as it was in the preceding case. Young people seem to know more about the percentage that is deducted from their pay in the form of social security taxes and about how their funds are being invested, but older adults show themselves to be more knowledgeable about retirement ages and the different types of pension systems. Adults in the intermediate age group appear to know the most about how pension funds are calculated and about how much they have in their accounts. Level of education once again appears to be a significant differentiating factor in terms of the results, with the biggest differentials (around or slightly higher than 30\%) being in the level of knowledge about the "solidarity insurance contribution" and about the different pension-fund investment options. The members of this group are the ones who know the least about retirement ages.

As far as inter-round differences are concerned, there does not, generally speaking, appear to be any clear-cut trend. People scored the highest on questions 1, 2, 4 and 6 in the 2004 round, the highest on questions 3, 10 and 11 in the 2006 round, and the highest on questions 5,8 and 9 in the 2009 round. The differentials between consecutive rounds are below 5\%, however, except for a $20 \%$ drop between the 2006 and 2009 rounds for the question regarding knowledge about the Voluntary Retirement Savings system. These coefficients were obtained after the panel was balanced, so the same people were the respondents in all of the rounds.

\section{(c) Principal Component Analysis of Ridit Scores (PRIDIT) indices}

In order to obtain the BFS and KPS indicators, interviewees' responses in each round were recoded using a psychometric methodology for analysing the principal score components (Lieberthal, 2008). A brief discussion concerning the PRIDIT methodology can be found in annex 1 . This is a non-parametric technique that has also been used by Lusardi, Mitchell and Curto (2012) in a similar context to reduce the restrictions associated with some of the assumptions that are implicit in the simple average. In particular, it makes it possible to give more weight to unusual responses in the final indicator (the RIDIT component) and to the responses to questions that appear to explain the responses given to other questions.

Table 6 provides a quantitative description of these indicators. It should be noted that the indicators constructed using this technique may take on negative values and that the values obtained are comparable only within their particular context (the BFS and KPS indicators cannot be compared to one another). In order to provide a point of reference, the last two columns of table 6 show the overall average for each indicator for all the rounds and the corresponding standard deviation.

TABLE 6

Indicators of financial literacy: averages, by round and category, 2006-2009

\begin{tabular}{|c|c|c|c|c|c|c|c|}
\hline \multirow{2}{*}{$\begin{array}{l}\text { Indicator } \\
\text { Round }\end{array}$} & \multicolumn{2}{|c|}{ BFS } & \multicolumn{2}{|c|}{ BFS (contributors only) } & \multicolumn{3}{|c|}{ KPS } \\
\hline & 2006 & 2009 & 2006 & 2009 & 2004 & 2006 & 2009 \\
\hline Total & 0.0166 & -0.0189 & 0.1406 & 0.1138 & 0.0918 & 0.1039 & 0.0324 \\
\hline Men & 0.0978 & 0.0710 & 0.1857 & 0.1648 & 0.1223 & 0.1410 & 0.0792 \\
\hline Women & -0.0634 & -0.1050 & 0.0840 & 0.0521 & 0.0543 & 0.0571 & -0.0237 \\
\hline Age $<35$ & 0.2332 & 0.2659 & 0.2611 & 0.3015 & 0.0871 & 0.1029 & 0.0704 \\
\hline $34<$ age $<55$ & 0.0676 & 0.0617 & 0.1417 & 0.1319 & 0.0543 & 0.0571 & -0.0237 \\
\hline Age $>54$ & -0.0716 & -0.1087 & 0.1025 & 0.0634 & 0.0767 & 0.0921 & 0.0109 \\
\hline Educ $<13$ & -0.1007 & -0.1296 & 0.0105 & -0.0038 & -0.0741 & -0.0590 & -0.1293 \\
\hline Educ $>12$ & 0.4562 & 0.4426 & 0.4967 & 0.4733 & 0.5706 & 0.5496 & 0.5270 \\
\hline Mean & \multicolumn{2}{|c|}{0.0000} & \multicolumn{2}{|c|}{0.1277} & \multicolumn{3}{|c|}{0.0777} \\
\hline Standard deviation & \multicolumn{2}{|c|}{0.7052} & \multicolumn{2}{|c|}{0.6936} & \multicolumn{3}{|c|}{0.7513} \\
\hline
\end{tabular}

Source: Prepared by the authors, on the basis of data from the Social Protection Survey.

Note: BFS: Basic financial skills; KPS: Knowledge about the pension system.

As can be seen from the analysis of the responses to the survey questions, men tended to exhibit a greater extent of FL than women did. This finding is corroborated by all of the indicators, with differentials of between approximately 0.10 and 0.25 standard deviations. The value of the BFS indicator appears to decline as people age, whereas the values of the kps indicator do not exhibit any clear-cut trend (see figure $1(\mathrm{~A}$ and $\mathrm{B})$ ). 
FIGURE 1

A. Average values for the BFS indicator, by age group, for each round (Confidence intervals of 10\%)

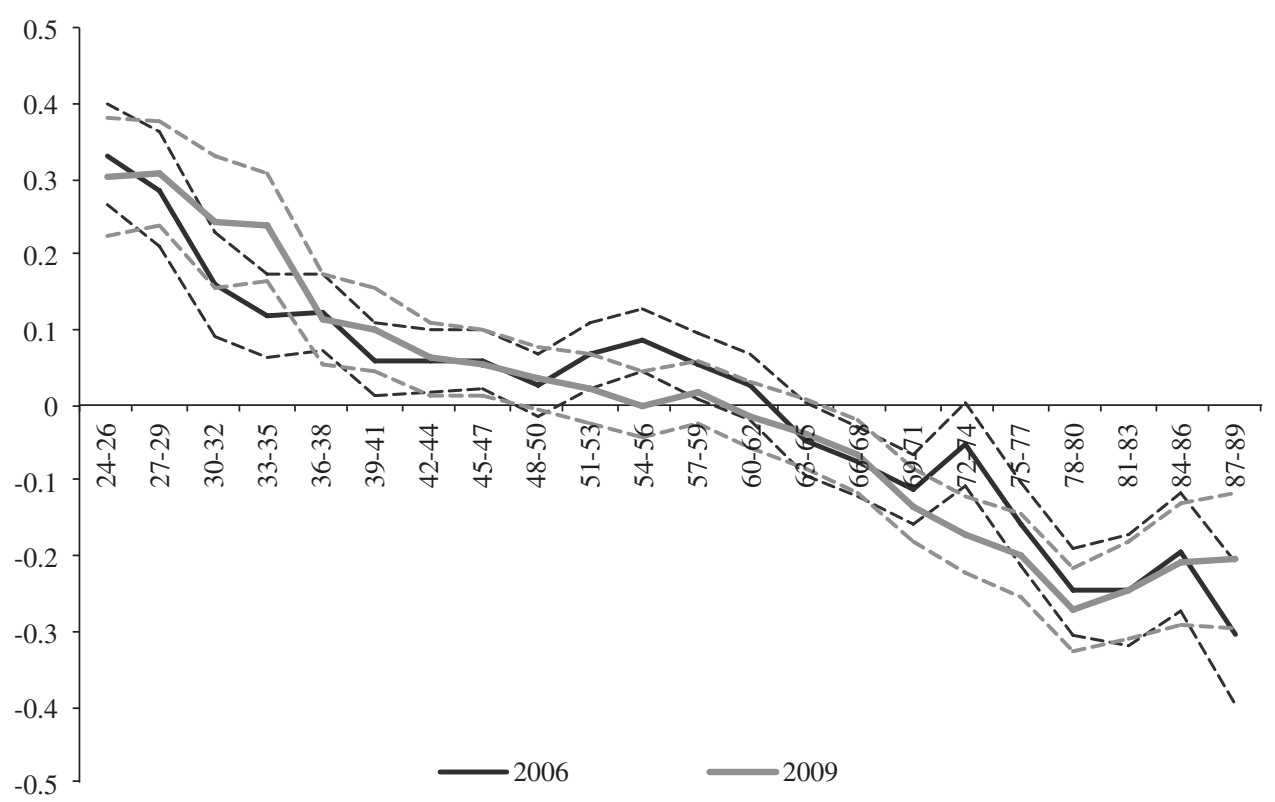

B. Average values for the KPS indicator, by age group, for each round (Confidence intervals of 10\%)

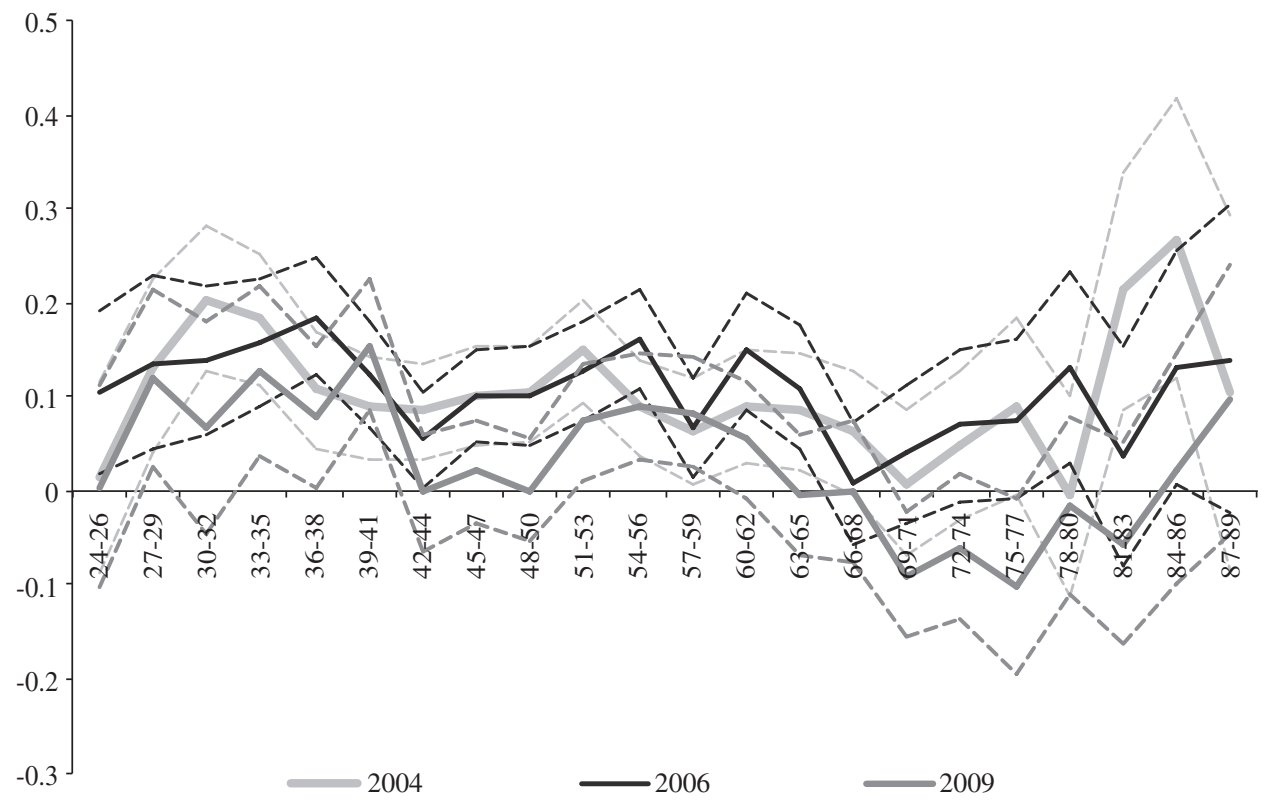

Source: Prepared by the authors, on the basis of data from the Social Protection Survey.

Note: BFs: Basic financial skills; KPS: Knowledge about the pension system.

The dotted lines indicate the confidence intervals. 


\section{Statistical analysis}

The statistical analysis focused on comparisons of the results for a given respondent as measured by the two FL indicators in consecutive rounds. The dependent variable is the change in the FL indicator and the independent variables are the occurrence or non-occurrence of the selected events. The 13 types of events are all included at one and the same time in the same regression.

Here too, a linear fixed-effect regression was used:

$$
\begin{gathered}
\Delta Y_{i t}=\sum_{j=1}^{17} \beta_{j} \Delta X_{i j t}+\Delta \text { income }_{i t} \\
+\Delta \text { household_income }{ }_{i t}+d_{\text {region } i t}+d_{34}+\delta+\Delta \varepsilon_{i t}
\end{gathered}
$$

where $Y$ corresponds to the knowledge indicator, $X$ to the vector for the 13 teachable moments, $\delta$ to the constant that captures the linear time effect; $\Delta$ income and sincome_household are the differentials in the logarithms for the income of the interviewee and for the rest of the household, respectively; $d_{\text {region }}$ is a dichotomous variable, by region; $d_{34}$ indicates whether the observation is for the period between 2006 and 2009; $i=1 . . N$ denotes the individual in question; and $t=1,2$ corresponds to 2006 or 2009 , respectively. It is assumed that the variables for all the rest of the observables and unobservables are sufficiently fixed to be eliminated from the model. The other assumptions are the same as they were for the preceding regressions.

\section{III}

\section{Results}

An analysis of the sample as a whole yields results (shown in the first column of table 7) that generally hold true for the subsamples (see the remaining columns in table 7) as well: only 1 of the 13 events that were selected is clearly associated with variations in the FL indicator. This event — job training — has a significant impact on both basic financial skills (BFS) and knowledge about the pension system (KPS), with coefficients of 0.271 and 0.630 for the PRIDIT indicators of BFS and KPS, respectively. This is far higher than the median for these indicators (around 0.10 in both cases). None of the other 12 events had a significant impact.

In the subsamples, the only education-related event that had an impact on FL was job training.
An analysis of the subsamples by sex, age and education yields some additional results but does not reflect any pattern that could be extrapolated to the overall sample. The most salient of these results have to do with the impact of changes in health status among women and among people below 54 years of age. In these subsamples, health-related events have a positive influence on BFS but a negative one on KPS. The possible explanations for this may include the presence of divergent patterns in the appreciation and depreciation of individuals' FL stocks or to movements into and out of the labour force.

In this study, all the regressions have been replicated using indicators calculated as simple averages rather than using principal components analysis of RIDIT scores (PRIDIT). The two exercises yielded similar results. 
TABLE 7

Results of the regressions

\begin{tabular}{|c|c|c|c|c|c|c|c|c|}
\hline Subsample & Total sample & Men & Women & Age $<35$ & $34<$ age $<54$ & $54<$ age & Educ $<=12$ & $12<$ educ \\
\hline Event & \multicolumn{8}{|c|}{ BFS indicator-total sample } \\
\hline Birth of a child & $0.154 * * *$ & 0.090 & $0.199 * * *$ & 0.066 & 0.057 & $0.267 * * *$ & $0.161 * *$ & 0.018 \\
\hline Marriage & 0.053 & 0.086 & 0.013 & -0.019 & 0.066 & 0.055 & 0.040 & 0.054 \\
\hline Widowed & -0.187 & -0.461 & -0.069 & $0.820 * * *$ & -0.427 & -0.149 & -0.120 & -0.130 \\
\hline Award of a professional degree & 0.180 & 0.045 & $0.274 *$ & $0.350 * *$ & -0.220 & -0.003 & - & $-0.231 *$ \\
\hline Award of a diploma & $0.129 *$ & 0.055 & 0.162 & -0.277 & 0.116 & $0.368 * *$ & $0.195^{* *}$ & $-0.255^{* *}$ \\
\hline Job training & $0.363 * * *$ & $0.334 * * *$ & $0.360 * * *$ & $0.290 * *$ & $0.288 * * *$ & $0.470 * * *$ & $0.297 * * *$ & 0.081 \\
\hline Learning a trade & 0.034 & $0.211^{*}$ & -0.131 & 0.075 & -0.032 & 0.130 & 0.024 & -0.093 \\
\hline Obtaining first permanent job & -0.060 & -0.030 & -0.052 & -0.096 & -0.096 & -0.083 & -0.033 & 0.030 \\
\hline Retirement & $-0.287 * * *$ & -0.299 & $-0.253 * * *$ & - & $-0.704 * * *$ & $-0.200 * * *$ & $-0.222 * * *$ & -0.039 \\
\hline Disablement & $-0.148 * *$ & $0.008 * * *$ & $-0.255 * * *$ & 0.059 & -0.032 & $-0.174 * *$ & $-0.145^{* *}$ & 0.128 \\
\hline $\begin{array}{l}\text { Termination of a period of } \\
\text { disablement }\end{array}$ & -0.056 & -0.030 & -0.079 & $0.902 * * *$ & 0.037 & -0.068 & 0.002 & -0.109 \\
\hline Improvement in health status & 0.105 & $-0.331 * *$ & $0.426 * * *$ & $0.560 * * *$ & $0.303 * *$ & -0.125 & 0.181 & $0.450 *$ \\
\hline Deterioration in health status & 0.029 & -0.032 & 0.042 & 0.024 & -0.016 & 0.044 & 0.065 & -0.110 \\
\hline Event & \multicolumn{8}{|c|}{ BFS indicator-persons paying into the pension system only } \\
\hline Birth of a child & $0.104^{*}$ & 0.052 & $0.139 *$ & 0.075 & 0.013 & $0.198 * *$ & $0.114 *$ & 0.010 \\
\hline Marriage & 0.027 & 0.012 & 0.045 & -0.140 & 0.099 & 0.009 & 0.005 & 0.027 \\
\hline Widowed & -0.389 & -0.116 & -0.493 & $0.758 * * *$ & $-0.918 * * *$ & $-0.509 * *$ & -0.392 & -0.256 \\
\hline Award of a professional degree & $0.196^{*}$ & 0.000 & $0.325 * * *$ & $0.358 * *$ & $-0.334 * *$ & 0.177 & - & -0.166 \\
\hline Award of a diploma & 0.059 & 0.019 & 0.083 & $-0.411 * * *$ & 0.110 & 0.241 & 0.129 & $-0.273 * *$ \\
\hline Job training & $0.271 * * *$ & $0.263 * * *$ & $0.274 * * *$ & $0.212 *$ & $0.228 * * *$ & $0.338 * * *$ & $0.212 * * *$ & 0.055 \\
\hline Learning a trade & -0.034 & $0.252 * *$ & $-0.248 * *$ & -0.001 & -0.141 & 0.138 & -0.020 & -0.121 \\
\hline Obtaining first permanent job & -0.066 & -0.038 & -0.067 & -0.193 & -0.063 & -0.032 & -0.073 & 0.101 \\
\hline Retirement & $-0.280 * *$ & $-0.431 * * *$ & 0.163 & - & $-0.942 * * *$ & $-0.189 *$ & $-0.195 *$ & -0.250 \\
\hline Improvement in health status & 0.057 & $-0.361 * *$ & $0.325 *$ & $0.517 * * *$ & $0.348 * *$ & -0.305 & 0.142 & $0.432 *$ \\
\hline Deterioration in health status & 0.045 & -0.089 & 0.163 & 0.091 & 0.008 & 0.041 & 0.051 & 0.020 \\
\hline Event & \multicolumn{8}{|c|}{ KPS indicator } \\
\hline Birth of a child & 0.087 & 0.039 & 0.125 & -0.026 & 0.058 & $0.249 * *$ & 0.105 & -0.020 \\
\hline Marriage & 0.124 & 0.116 & 0.105 & 0.207 & -0.048 & 0.207 & 0.122 & 0.060 \\
\hline Widowed & -0.489 & -0.227 & $-0.613 * *$ & $0.988 * * *$ & $-0.735 * * *$ & $-0.635 *$ & -0.453 & $-0.594 * * *$ \\
\hline Award of a professional degree & -0.004 & 0.105 & -0.062 & -0.212 & -0.166 & 0.256 & - & $-0.444 * * *$ \\
\hline Award of a diploma & $0.392 * * *$ & $0.546^{* * *}$ & $0.259 * *$ & $0.315^{*}$ & $0.336 * * *$ & $0.585 * * *$ & $0.341 * * *$ & $0.184 * *$ \\
\hline Job training & $0.630 * * *$ & $0.646^{* * *}$ & $0.623 * * *$ & $0.709 * * *$ & $0.624 * * *$ & $0.607 * * *$ & $0.609 * * *$ & $0.301 * * *$ \\
\hline Learning a trade & $0.241 * * *$ & $0.289 * *$ & 0.188 & 0.001 & 0.161 & $0.468 * * *$ & $0.249 * * *$ & 0.138 \\
\hline Obtaining first permanent job & $-0.214 * *$ & -0.015 & $-0.325 * * *$ & -0.141 & $-0.391 * * *$ & -0.016 & $-0.226 * * *$ & -0.023 \\
\hline Retirement & -0.209 & -0.210 & -0.155 & - & $-0.743 * * *$ & -0.155 & -0.071 & -0.436 \\
\hline Disablement & $-0.211 * *$ & -0.147 & $-0.308 * *$ & -0.108 & 0.013 & $-0.431 * * *$ & $-0.224 * * *$ & -0.108 \\
\hline $\begin{array}{l}\text { Termination of a period of } \\
\text { disablement }\end{array}$ & -0.148 & -0.130 & -0.183 & 0.000 & $-0.239 *$ & -0.089 & -0.132 & 0.042 \\
\hline Improvement in health status & $-0.343 * * *$ & $-0.407 * *$ & $-0.285^{*}$ & $-0.861 * * *$ & $-0.349 * *$ & -0.282 & $-0.206^{* *}$ & -0.348 \\
\hline Deterioration in health status & 0.099 & -0.067 & 0.232 & $0.537 * * *$ & 0.168 & -0.114 & 0.118 & 0.098 \\
\hline
\end{tabular}

Source: Prepared by the authors, on the basis of data from the Social Protection Survey.

Note: BFS: Basic financial skills; KPS: Knowledge about the pension system.

* Significant at $10 \%$; ** significant at $5 \%$; *** significant at $1 \%$. 


\section{IV}

\section{Discussion}

Given the importance that is generally ascribed to financial literacy (FL) in terms of its implications for people's well-being, and in view of a number of studies that indicate that the population's level of FL is quite low, various government programmes designed to increase the population's level of FL have been introduced. There is, however, no consensus in the literature as to the effectiveness of these programmes or about the robustness of the current conceptual approach to FL.

According to the most prevalent way of thinking about FL (referred to here as the "economic model of FL"), people decide how much FL to acquire based on the expected benefits that it will yield in terms of decisionmaking. In this study, however, the economic model of FL did not fit the data very well, since the analysis did not turn up conclusive evidence of an increase in people's FL when they experienced events that are associated with changes in financial status. This conclusion was reached by analysing two different indicators of FL, both in conjunction with one another and separately, on the basis of a panel of over 12,000 respondents who were surveyed up to four times within seven years. This sample was also divided up into several subsamples.

ANNEX 1

\section{PRIDIT}

PRIDIT (i.e., principal component analysis of RIDIT scores) is a non-parametric aggregation technique that involves using two different procedures to rank samples based on categorical observables (Lieberthal, 2008).

The RIDIT methodology has been developed to analyse categorical (in this case, binary) variables serving as proxies for unobservables (Lieberthal, 2008). The underlying reason for using the ridit methodology in this study is that an incorrect response may provide more information about a person's level of FL than a correct one, and vice versa. This is because there are some questions that most people answer correctly and, in these cases, the incorrect answers allow us to identify a particular group of individuals; by the same token, when dealing with questions that most people get wrong, the correct answers provide us with more information.
In short, it is not clear that the economic model is a good fit for FL. While some criticism might be aimed at this study in terms of the quality of the data or of the FL indicators or the validity of the empirical strategy that it has employed, the fact remains that it backs up a number of other studies that have, for one reason or another, cast doubt upon the soundness of the current construct of FL.

It is possible that FL cannot be reduced to a simple concept. Even in a more general context, information goods are quite complex (Bates, 1990; Rafaeli and Raban, 2003). It may also be that FL should be viewed as an individual trait which, like intelligence, does not change in the short run. A model of fluid intelligence versus crystalized intelligence has been proposed that may help us to come to grips with a possible association between FL and age (Agarwal and others, 2009). Or perhaps FL is more a matter of attitude than of knowledge per se. Yet another possibility, which would not preclude the preceding one, is that individuals update their FL in ways that cause it to appreciate and/ or depreciate such that the net variation in FL is usually very small.
Assigning ones and zeros to all correct and incorrect answers as a basis for constructing the indicator presupposes, first, that FL is metrically measurable - an assumption that we will not take exception to- and, second, that the metric can be scaled with equal intervals between responses for each survey question (Brockett and others, 2002). RIDIT deals with this problem by using sample information for each question to assign different values or weights to the responses (Lieberthal, 2008).

In line with Brockett and others (2002), the following algorithm was used to construct the RIDIT scores in this study: $\hat{p}_{t i}$ is the sample probability of obtaining answer $i$ for question $t$, where $i=0,1$ is the number of categories corresponding to answer $t$. RIDIT scores are therefore determined as follows:

$$
R_{t i}=\sum_{j<i} \hat{p}_{t j}-\sum_{j>i} \hat{p}_{t j}
$$


Thus, rather than assigning zeros and ones, we assign $R_{t 0}$ and $R_{t 1}$ to the answers to each question $t$. This score rises monotonically in the different categories, with the original classification being maintained at the same time that $E\left(R_{t}\right)=0$ is fulfilled. In the words of Brockett and others (2002), this method "eliminates the necessity of assigning integer values in an ad hoc fashion and improves the statistical characteristics of the resulting scored data for subsequent standard statistical analysis, whatever it is" (Brockett and others, 2002).
PRIDIT: once the RIDIT scores for each question have been obtained, the principal component analysis weights the questions on the basis of how important a role the play in terms of the variance of the final scores. A convergent algorithm is used to compute the weightings, with the questions that are the least correlated with a linear combination of the other questions being given a greater weighting, since they are the ones that provide the most information. In other words, greater attention is devoted to the "strangest" answers when the time comes to compute the final scores (Lusardi, Mitchell and Curto, 2012).

\section{Bibliography}

Agarwal, S. and others (2009), "The age of reason: financial decisions over the life-cycle with implications for regulation", Brookings Papers of Economic Activities, vol. 40, No. 2, Washington, D.C., The Brookings Institution.

Bates, B.J. (1990), "Information as an economic good: a re-evaluation of theoretical approaches", Mediation, Information, and Communication. Information and Behavior, B.D. Ruben and L.A. Lievrouw (eds.), New Brunswick, Transaction Publishers.

Bravo, D. and others (2008), Determinantes del Ahorro Previsional Voluntario en Chile, Santiago, Microdata Centre, Department of Economics, University of Chile.

(2006), "Encuesta de Protección Social 2004: presentación general y principales resultados" [online] http://www.previsionsocial. gob.cl/subprev/?wpfb_dl=17.

(2004), Análisis y principales resultados. Primera Encuesta de Protección Social. Historia laboral y seguridad social, Santiago, University of Chile.

Brockett, P.L. and others (2002), "Fraud classification using principal component analysis of ridits", The Journal of Risk and Insurance, vol. 69 , No. 3, Wiley.

Campbell, J.Y. and others (2011), "Consumer financial protection", Journal of Economic Perspectives, vol. 25, No. 1, Nashville, Tennessee, American Economic Association.

Chan, S. and A. Huff (2003), "What you don't know can't help you: pension knowledge and retirement decision making", NBER Working Paper, No. 10185, Cambridge, Massachusetts, National Bureau of Economic Research.

Christelis, D., T. Jappelli and M. Padula (2005), "Health risk, financial information and social interactions: the portfolio choice by European elderly households", Working Paper, University of Salerno.

Delavande, A., S. Rohwedder and R. Willis (2008), "Preparation for retirement, financial literacy and cognitive resources", Working Paper, No. 190, Michigan, University of Michigan.

Demark-Wahnefried, W. and others (2005), "Riding the crest of the teachable moment: promoting long-term health after the diagnosis of cancer", Journal of Clinical Oncology, vol. 23, No. 24, New York, American Society of Clinical Oncology.

Fajnzylber, E., G. Plaza and G. Reyes (2009), "Better-informed workers and retirement savings decisions: impact evaluation of a personalized pension projection in Chile", Working Paper, No. 31, Santiago, Chilean Pensions Supervisor.

GAO (Government Accountability Office) (2004), "Highlights of a GAO Forum: the Federal Government's Role in Improving Financial Literacy" [online] http://www.gao.gov/products/gao-05-93SP.
Gerardi, K., L. Goette and S. Meier (2010), "Financial literacy and subprime mortgage delinquency: evidence from a survey matched to administrative data", Working Paper Series, No. 2010-10, Atlanta, Federal Reserve Bank of Atlanta.

Hansen, E.J. (1998), "Creating teachable moments... and making them last", Innovative Higher Education, vol. 23, No. 1, Springer.

Hastings, J. and L. Tejeda-Ashton (2008), "Financial literacy, information, and demand elasticity: survey and experimental evidence from Mexico", NBER Working Paper, No. 14538, Cambridge, Massachusetts, National Bureau of Economic Research.

Hathaway, I. and S. Khatiwada (2008), "Do financial education programs work?", Working Paper, No. 08-03, Cleveland, Federal Reserve Bank of Cleveland.

Hilgert, M.A., J.M. Hogarth and S.G. Beverly (2003), "Household financial management: the connection between knowledge and behavior", Federal Reserve Bulletin, vol. 89, No. 7.

Hogarth, J. and M. Hilgert (2002), "Financial knowledge, experience and learning preferences: preliminary results from a new survey on financial literacy", Consumer Interests Annual, vol. 48, No. 1.

Huston, S.J. (2010), "Measuring financial literacy”, Journal of Consumer Affairs, vol. 44, No. 2, Wiley.

Landerretche, O. and C. Martínez (2011), "Voluntary savings, financial behavior and pension finance literacy: evidence from Chile", Working Paper, No. 328, Santiago, Department of Economics, University of Chile.

Lieberthal, R.D. (2008), "Hospital quality: a PRIDIT approach", Health Services Research, vol. 43, No. 3, Chicago, Health Research \& Educational Trust, June.

Liker, J.K., S. Augustyniak and G.J. Duncan (1985), "Panel data and models of change: a comparison of first difference and conventional two wave models", Social Science Research, vol. 14, No. 1, Amsterdam, Elsevier.

Lusardi, A. (2008), "Financial literacy: an essential tool for informed consumer choice?", CFs Working Paper Series, No. 19, Center for Financial Studies.

Lusardi, A. and O. Mitchell (2007a), "Baby boomer retirement security: the role of planning, financial literacy, and housing wealth", Journal of Monetary Economics, vol. 54, No. 1, Amsterdam, Elsevier.

(2007b), "Financial literacy and retirement preparedness: evidence and implications for financial education", Business Economics, vol. 42, No. 1.

(2006), "Financial literacy and planning: implications for retirement and wellbeing", DNB Working Paper, No. 078, Netherlands Bank. 
Lusardi A., O. Mitchell and V. Curto (2012), "Financial sophistication in the older population", NBER Working Paper, No. 17863, Cambridge, Massachusetts, National Bureau of Economic Research.

(2010), "Financial literacy among the young", Journal of Consumer Affairs, Special Issue on Financial Literacy, vol. 44, No. 2, Wiley.

Lyons, A.C. and others (2006), "Are we making the grade? A national overview of financial education and program evaluation", Journal of Consumer Affairs, vol. 40, No. 2, Wiley.

Mason, C. and R. Wilson (2000), "Conceptualizing financial literacy", Research Series Paper, No. 7, London, Business School, Laughborough University.

Mandell, L. and L.S. Klein (2009), "The impact of financial literacy education on subsequent financial behavior", Journal of Financial Counseling and Planning, vol. 20, No. 1.

(2007), "Motivation and financial literacy", Financial Services Review, vol. 16, No. 2.

McBride, C.M., K.M. Emmons and I.M. Lipkus (2003), "Understanding the potential of teachable moments: the case of smoking cessation", Health Education Research, vol. 18, No. 2, Oxford, Oxford University Press.

McBride, C.M. and J.S. Ostroff (2003), "Teachable moments for promoting smoking cessation: the context of cancer care and survivorship", Cancer Control, vol. 10, No. 4.

Miles, D. (2004), The UK Mortgage Market: Taking a Longer-Term View", London, The Stationery Office.
Rafaeli, S. and D.R. Raban (2003), "Experimental investigation of the subjective value of information in trading", Journal of the Association for Information Systems, vol. 4, No. 1.

Remund, D.L. (2010), "Financial literacy explicated: the case for a clearer definition in an increasingly complex economy", Journal of Consumer Affairs, vol. 44, No. 2, Wiley.

Servon, L.J. and R. Kaestnert (2008), "Consumer financial literacy and the impact of online banking on the financial behavior of lower-income bank customers", Journal of Consumer Affairs, vol. 42, No. 2, Wiley.

Stone, L.O. and B. Neumann (2012), "Gender differences in preparedness to meet retirement's challenges", Key Demographics in Retirement Risk Management, L. Stone (ed.), Springer.

Syvertzen, A.K., M.D. Stout and C.A. Flanagan (2009), "Using elections as teachable moments: a randomized evaluation of the student voices civic education programs", American Journal of Education, vol. 116, No. 1, Chicago, University of Chicago Press.

Van Rooij, M., A. Lusardi and R. Alessie (2011), "Financial literacy and stock marker participation", Journal of Financial Economics, vol. 101, No. 2, Amsterdam, Elsevier.

Willis, L.E. (2009), "Evidence and ideology in assessing the effectiveness of financial literacy education", San Diego Law Review, vol. 46, San Diego, University of San Diego.

(2008), "Against financial-literacy education", Iowa Law Review, vol. 94, Iowa. 